\title{
When Targets Strike Back: How Negative Workplace Gossip Triggers Political Acts
}

\section{by Employees}

Bao Cheng, Yun Dong, Zhenduo Zhang, Ahmed Shaalan, Gongxing Guo \& Yan Peng

\begin{abstract}
This study examines why and when negative workplace gossip promotes self-serving behaviors by the employees being targeted. Using conservation of resources (COR) theory, we find that targets tend to increase their political acts as a result of ego depletion triggered by negative gossip. We also show that sensitivity to interpersonal mistreatment and moral disengagement moderate this process. Specifically, we demonstrate that targets with high levels of sensitivity to interpersonal mistreatment are more likely to experience ego depletion, and that targets with high levels of moral disengagement will find it easier to persuade themselves to engage in political acts. We conducted a three-wave time-lagged survey of 265 employees in Guangdong, China, to test our hypotheses. The results support our theoretical model and indicate that COR theory can be used to explain the impacts of negative workplace gossip. Alongside our important and timely theoretical contributions, we provide new perspectives on how managers can avoid or mitigate these political acts.
\end{abstract}

Keywords: negative workplace gossip, political acts, moral disengagement 


\section{Introduction}

Gossip is a common social phenomenon: most people engage in it or are targeted by it at different times in their everyday lives. Research has shown that more than half of the time that people spend talking is devoted to gossip (Dunbar 2004). At work, employees find that gossip is an important informal communication tool, and often participate in it to gather and exchange information (Beersma and Van Kleef 2011; Kniffin and Wilson 2010; Kuo et al. 2015; Mills 2010) and to satisfy their social needs (Brady et al. 2017). Given its prevalence, researchers have paid much attention to its influence in organizations. They have found that workplace gossip can benefit organizations, groups and gossips to a certain extent (Beersma and Van Kleef 2011; Feinberg et al. 2012; Michelson and Mouly 2002), but targeted employees may suffer significant harm, especially from negative gossip (Kuo et al. 2015; Wu et al. 2018b), since people have greater sensitivity to negative events than to positive ones (Baumeister et al. 2001), and this alters their behavior in the workplace. An increasing number of studies has therefore investigated negative workplace gossip from the perspective of the targets and its impact on them.

Previous research has employed different perspectives to explain the impact of negative workplace gossip on targets, such as social exchange (Lee et al. 2016), social identity (Ye et al. 2019) and resource-based perspective (Xie et al. 2019), resulting in insightful findings. Some studies have confirmed the detrimental impact of gossip on targets' attitudes and behaviors, such as reducing their organization-based self-esteem (Zhou et al. 2019), lowering organizational identification (Ye et al. 2019), raising organizational 
cynicism (Kuo et al. 2015), increasing emotional exhaustion (Wu et al. 2018b), promoting negative mood (Babalola et al. 2019), and causing a decline in engagement (Georganta et al. 2014), innovative behavior (Zhou et al. 2019), proactive behavior (Tian et al. 2019; Wu et al. 2018b) and organizational citizenship behavior (Wu et al. 2018a).

Although negative workplace gossip from the targets' perspective has received a great deal of attention, the previous research still has some limitations. Firstly, there is a lack of full understanding, from a resource-based perspective, of the whole range of targets' responses. Prior studies (Liu et al. 2020; Wu et al. 2018b; Xie et al. 2019) have shown that targets suffer damage to their valuable resources (e.g., emotional resources) or find themselves in a state of lack of resources (e.g., emotional exhaustion), with the result that they devote less effort to their work in order to protect their remaining resources; the effects include reductions in creativity and proactive behavior (Liu et al. 2020; Wu et al. 2018b). However, the current literature describes only a relatively passive reaction by targets to protect their resources, whereby they reduce the valuable resources they invest in their work. These studies seem to neglect the possibility that some individuals may have strong incentives to make every effort to extract themselves from trouble by taking proactive steps to gain new resources, a possibility which is also emphasized by COR theory (Hobfoll 1989; Hobfoll et al. 2018). In other words, targets may actively maximize instrumental behaviors in order to strive for additional resources, rather than just protecting their existing resources (Hobfoll 1989; Hobfoll et al. 2018). For example, to gain new resources they may engage in political acts - self-serving behaviors aiming at maximizing one's self-interests by 
influencing the thinking, perception or behaviors of other members of an organization (Buchanan 2008; Ferris et al. 1989; Mayes and Allen 1977). Therefore, on the basis of COR theory, this paper adds to the knowledge by demonstrating that, in addition to the broadly passive responses by targets of negative workplace gossip that have been previously identified, some targets may make proactive responses, including by carrying out political acts in order to facilitate access to new resources. Moreover, as political acts can influence other members' interests and even organizational goals (Chang et al. 2009; Ferris et al. 1989), it is essential to explore why employees engage in self-serving behaviors of this type. By examining this issue through the prism of a common workplace phenomenon, namely negative workplace gossip, we therefore expand the current literature on the antecedents of political acts, which until now have been considered in terms of limited individual and contextual factors (Buchanan 2008).

Secondly, the underlying mechanism of how negative workplace gossip influences targets' behavior still needs to be better understood. Most of the previous research in this area focuses on the change in targets' emotions or their attitudes towards the organization, such as negative mood, organization-based self-esteem and organizational identification (Babalola et al. 2019; Wu et al. 2018b; Ye et al. 2019; Zhou et al. 2019). However, as a common, indirect and harmful phenomenon for targets, negative workplace gossip may also trigger cognitive reactions (Ye et al. 2019). For example, employees may not easily discover that they are the targets of gossip, but may perceive it from their colleagues' unusual behaviors and the strange ambience around them (Babalola et al. 2019; Foster 2004; Wu et 
al. 2018b). They may also struggle to find out who is responsible, and may have to suppress negative emotions. All these aspects of being targeted deplete valuable resources related to attention and cognitive activities (Baumeister 2003; Baumeister et al. 2007), leading to a state of ego depletion. By investigating this ego depletion, we can gain a comprehensive understanding of the underlying mechanism of negative workplace gossip.

Thirdly, as negative workplace gossip occurs without the presence of the targets (Kurland and Pelled 2000) and is indirect and stealthy (Kuo et al. 2015; Wu et al. 2018b), its influence on targets depends on the extent to which they can perceive and interpret it (Ye et al. 2019). As individuals differ in their perceptions of how others treat them (Bunk and Magley 2011), it is therefore important to explore sensitivity to interpersonal mistreatment, i.e., the difference in individuals' perceptual level of interpersonal mistreatment (Bunk and Magley 2011; Li et al. 2016), since this drives not only their level of awareness of mistreatment but the strength of their reaction to it (Bunk and Magley 2011; Li et al. 2016). This is particularly relevant to the present study since individuals with high levels of the trait of sensitivity tend to perceive negative workplace gossip more quickly and in a more intensive manner than others, and are likely to react to it in a stronger way, which may strengthen its impact. Another unexplored deposit is that of moral disengagement, which justifies individuals' engagement in immoral behaviors (Bandura 1999, 2002; Liu and Berry 2013; Moore et al. 2012). When experiencing ego depletion caused by negative workplace gossip, targets with high levels of moral disengagement are more likely to engage in selfserving behaviors such as political acts in order to gain benefits. Therefore, we expect 
sensitivity to interpersonal mistreatment and moral disengagement to affect the first and second stages of our mediation model respectively, since the former relates to individuals' evaluation of and response to negative workplace gossip (Li et al. 2016) and the latter concerns how individuals justify their engagement in self-serving behaviors after ego depletion (Moore et al. 2012).

On the basis of this reasoning, this study proposes an integrated framework to verify sensitivity to interpersonal mistreatment and moral disengagement as moderators of the indirect links between negative workplace gossip and political acts through ego depletion. Fig. 1 shows the conceptual model.

[Fig. 1 near here]

\section{Theoretical Background and Hypothesis Development}

\subsection{Negative Workplace Gossip}

Negative workplace gossip can be defined as informal, negative and evaluative discussions among organization members about an absent third member of the organization (Chandra and Robinson 2009; Foster 2004; Kurland and Pelled 2000; Wu et al. 2018b). It has three significant features. Firstly, the information it conveys is negative and evaluative, and is aimed at an organization member (Foster 2004; Kurland and Pelled 2000; Wu et al. 2018b).

This kind of gossip usually relates to the target's privacy, and normally involves material that is sensitive, personal or cannot be unveiled in public (Kuo et al. 2015), such as cyberloafing, divorce or affairs (Kuo et al. 2015; Michelson and Mouly 2002). This unfavorable information may put targets at a disadvantage in the organization ( $\mathrm{Wu}$ et al. 
2018b) and/or destroy their reputation (Kuo et al. 2015). Secondly, negative workplace gossip is indirect and stealthy (Kuo et al. 2015; Wu et al. 2018b). Unlike other types of mistreatment, such as workplace violence (Neuman and Baron 1998) and sexual harassment (Li et al. 2016), negative workplace gossip does not attack targets face-to-face. As a form of informal communication in organizations (Ellwardt et al. 2012; Foster 2004; Kurland and Pelled 2000), it usually occurs in a familiar and private context (Grosser et al. 2012; Kuo et al. 2015; Michelson and Mouly 2002; Wu et al. 2018b), and the targets are absent from the process (Kurland and Pelled 2000). Thirdly, negative workplace gossip spreads very fast, and, because the targets are not present, it is difficult for them to find the source or know the detailed content (Wu et al. 2018b). These factors make it difficult to stop the spread of gossip, and the targets are unable to adopt a direct confrontational method to cope with the situation.

\subsection{Negative Workplace Gossip and Political Acts}

Political acts are self-serving behaviors aiming at maximizing one's self-interests by influencing the thinking, perception or behaviors of other members of an organization (Buchanan 2008; Ferris et al. 1989; Mayes and Allen 1977). Employees engage in such behaviors for their own benefit because acting politically facilitates them to gain valuable resources such as rewards, favor and reputation (Drory and Romm 1990; DuBrin 2009; Landells and Albrecht 2017). For example, employees can act politically by building informal relationships and use these to influence the distribution of organizational resources (Drory and Romm 1990): this can achieve the intentions of the actors but may adversely 
impact the interests of other members of the organization (Chang et al. 2009), or even affect the goals of the organization as a whole (Ferris et al. 1989). It is therefore important to uncover the precursors of political acts.

In this study, we propose that the targets of negative workplace gossip may have strong motivations to engage in political acts as a reaction to protect themselves. According to COR theory, individuals are sensitive to the loss of resources and have a tendency to preserve, protect and gain valuable resources; COR theory further emphasizes that individuals attempt to invest their present resources to get access to new resources, and to recover from and fight against losses (Hobfoll 1989; Hobfoll et al. 2018). This means they have strong incentives to make efforts to invest their current resources to cope with unfavorable situations such as actual or potential resource loss. For example, employees invest valuable resources such as knowledge, time and emotions into their work in exchange for desirable outcomes such as higher salaries and promotion. However, negative workplace gossip undermines this process, which means that employees gain fewer resources at a higher cost. Targets are therefore likely to engage in self-serving behaviors which aims at maximizing their benefits, such as political acts to address this unsatisfactory situation and to reduce their losses and strive for more available resources. The drivers of this behavior are set out in the following paragraphs.

Firstly, negative workplace gossip usually includes negative evaluation of the targets. It endangers their reputation (Wu et al. 2016) and even damage their professional position (Michelson and Mouly 2002), because, regardless of its authenticity, those who hear it tend 
to believe it (Michelson and Mouly 2002). Furthermore, reputation and professional ability are workplace assets, without which targets may fail to compete with colleagues for promotions and other advantages (Blickle et al. 2011). Secondly, negative workplace gossip creates situations in which the targets are excluded from a group by other members of an organization (Beersma and Van Kleef 2011), resulting in a loss of support and reduced chances to cooperate with and gather important information from colleagues - processes which are directly related to future desirable resources from organizations (Drory and Romm 1990; Langford 2000; Liden et al. 2000). Thirdly, when targets perceive the existence of negative gossip, they feel embarrassed and uncomfortable (Kuo et al. 2015) given its impacts on their reputation and even their career development. They may also devote valuable resources such as time and energy to verifying the source of the gossip (Dunbar 2004) as well as working out how to cope with it - resources which would otherwise have been put into their work in exchange for more a meaningful outcome. Overall, it can be seen that targets have to face multiple disadvantages and dilemmas, and therefore feel an urgent need to take action to affect the thinking, perceptions or behaviors of other members of the organization (Buchanan 2008; Ferris et al. 1989; Mayes and Allen 1977), in order to reacquire support and other desired results. In pursuit of these goals, they are more likely to engage in political acts, for example seeking to rebuild relationships within the organization and then making use of them to reverse the disadvantageous situation. The feelings of uncertainty and ambiguity triggered by their perceptions of negative gossip are also likely to pave the way for political acts (Elbanna et al. 2014). Therefore, we posit the following 
hypothesis:

Hypothesis 1: Negative workplace gossip is positively related to political acts.

\subsection{Negative Workplace Gossip, Ego Depletion and Political Acts}

COR theory considers resources to be anything that can help individuals achieve their goals (Halbesleben et al. 2014). For example, individuals rely on psychological resources, which are related to volitional and cognitive activities, to focus their full attention on an issue or to carry out cognitive tasks (Baumeister 2003; Baumeister et al. 2007), in areas such as understanding blurred and complex information (Rosen et al. 2016; Schmeichel et al. 2003), suppressing emotions (Baumeister 2002) and controlling impulsive behavior (Schmidt and Neubach 2007). However, when resources such as these are depleted and cannot be replenished, individuals will fall into a state of ego depletion (Baumeister et al. 2007; Hagger and Chatzisarantis 2016), i.e. they are in a state of lack of resources. Research has confirmed that ego depletion affects individuals' subsequent behavior, for example creating an increased likelihood that they will take risks (Fischer et al. 2012) or engage in unethical behavior (Gino et al. 2011).

Negative workplace gossip tends to cause ego depletion because it generally consumes targets' psychological resources. This happens in a number of ways. Firstly, psychological resources will be consumed because targets' time and attention are devoted to the process of finding out they are being targeted. As they are isolated from the conversation about them (Kurland and Pelled 2000), they cannot directly find out the contents of the gossip. However, they may perceive their colleagues' unusual behaviors and a strange ambience (Babalola et 
al. 2019; Foster 2004; Wu et al. 2018b), and may then continue to invest resources in analyzing this ambiguous information until they infer that they are being gossiped about. Notably, this thinking process may last a long time because targets may wonder if they have done something wrong, eating still further into their attention and cognitive resources. Secondly, targets usually experience a negative mood after it is confirmed that that they are the center of gossip (Babalola et al. 2019). They may be embarrassed about the disclosure of private information, be worried about their damaged reputation, and feel hopeless. All these negative feelings will further consume their limited psychological resources. Thirdly, research has shown that targets are likely to be excluded by other members of an organization (Beersma and Van Kleef 2011), which hampers them in carrying out their work. Therefore, they have to become more cautious about how they speak and act in the workplace, which accelerates the depletion of their resources.

On the basis of the reasoning set out above, we suggest that negative workplace gossip increases the loss of targets' resources and causes them to experience a state of ego depletion. COR theory suggests that individuals cherish their current resources and are motivated to gain new resources as supplements when they find their existing ones are decreasing (Hobfoll 1989). In other words, they not only take action to prevent the loss of resources but also engage in behavior that will help them acquire new ones (Hobfoll et al. 2018). Targets of negative gossip are therefore likely to perform political acts in order to devote their precious remaining resources to preventing further losses while also acquiring new resources. Therefore, we posit the following hypothesis: 
Hypothesis 2: Ego depletion mediates the positive relationship between negative workplace gossip and political acts.

\subsection{The Moderating Roles of Sensitivity to Interpersonal Mistreatment and Moral}

\section{Disengagement}

Research has shown that negative workplace gossip can be perceived by the target, and that the degree of its impact is determined by the target's personal disposition (Babalola et al. 2019; Wu et al. 2018b; Ye et al. 2019). In other words, the strength of individuals' awareness of and reaction to how others treat them plays an important role in the impact of negative workplace gossip. This can be measured as sensitivity to interpersonal mistreatment, which describes the difference between individual responses when interpersonal mistreatment occurs in employees' interactions with both supervisors and coworkers (Bunk and Magley 2011; Li et al. 2016). It is worth emphasizing here that sensitivity to interpersonal mistreatment measures not only individuals' awareness of interpersonal mistreatment but also their responsiveness to it (Bunk and Magley 2011). In other words, it signals the intensity of an individual's cognitive and affective responsiveness to interpersonal negative behavior towards them, such as sexual harassment ( $\mathrm{Li}$ et al. 2016). Individuals with higher sensitivity to interpersonal mistreatment are more prone to capturing unfavourable treatment and to generating stronger emotions, and are more likely to fight back in a stronger way. In contrast, those who are less sensitive to interpersonal mistreatment are less aware of when they are being mistreated and prefer to neglect and care less than other groups about such behaviors (Li et al. 2016). 
Sensitivity to interpersonal mistreatment may therefore moderate the relationship between negative workplace gossip and ego depletion. When faced with negative gossip, employees with high levels of sensitivity will be more conscious of it and will experience more intense negative emotions such as anxiety and fear. Moreover, they will devote more time and attention to finding ways to react to this unfavorable situation. This will accelerate their loss of emotional and mental resources, leading to a higher level of ego depletion. On the contrary, employees with low levels of sensitivity to interpersonal mistreatment may not take negative gossip seriously and will spend less time and attention responding to it, expending fewer emotional and mental resources and thus experiencing a lower level of ego depletion. On this basis of this reasoning, we propose that high sensitivity to interpersonal mistreatment may exacerbate the relationship between negative workplace gossip and ego depletion. We therefore hypothesize that:

Hypothesis 3: Sensitivity to interpersonal mistreatment moderates the relationship between negative workplace gossip and ego depletion, such that the relationship is stronger when targets' sensitivity to interpersonal mistreatment is higher.

Individuals usually suffer when they engage in behaviors that breach their moral standards (Bandura et al. 1996), because they normally manage their own behaviors by selfregulation and will feel self-censured if they break their own standards (Bandura 1991). However, this self-regulation process can be destroyed when individuals reframe their 
behaviors by downplaying the importance of ethical principles. Once this process has been invalidated, individuals will ignore their own ethical principles more easily and are more likely to engage in behaviors that breach their own standards without feeling guilty (Bandura 1991; Moore et al. 2012). The reason why certain individuals engage in behaviors that conflict with their own moral rules can be explained by their dispositional moral disengagement, which is defined as the difference in their cognitional process decisions whereby they permit themselves to engage in behaviors that are inconsistent with their moral standards without feeling distress (Bandura 1999, 2002; Liu and Berry 2013; Moore et al. 2012). Research has shown that moral disengagement is a useful index in predicting individuals' behaviors (Detert et al. 2008; Moore et al. 2012).

Therefore, we posit that moral disengagement is a key factor that moderates the relationship between ego depletion and political acts. When faced with ego depletion, individuals with high levels of moral disengagement are more likely to engage without feeling guilty in self-serving behaviors such as political acts that aim to protect their own benefits and maximize their self-interests (Chang et al. 2009; Ferris et al. 2002; Turnley and Bolino 2001). They may justify their self-serving behaviors in several ways to alleviate selfcensure, such as advantageous comparison and attribution of blame (Bandura et al. 1996). For example, individuals who engage in political acts may compare their conduct with more serious acts such as violence, in order to make their own behaviors seem less harmful and more acceptable. Moreover, individuals may attribute their ego depletion to their colleagues' disrespect of them, and by attributing blame to the troublemakers (Bandura et al. 1996), they 
perceive their political acts to be reasonable, freeing them from self-censure. On the other hand, individuals with low levels of moral disengagement are more sensitive to behaviors that are aimed at benefiting themselves, and will experience psychological discomfort if they carry out self-serving behaviors (Bandura 1999). Thus, they are less likely to commit political acts. We therefore hypothesize that:

Hypothesis 4: Moral disengagement moderates the relationship between ego depletion and political acts, such that the relationship is stronger when targets' moral disengagement is high.

Thus far, this study has developed a theoretical framework in which ego depletion mediates the influence of negative workplace gossip on political acts, while sensitivity to interpersonal mistreatment is a moderator that amplifies the effect of negative workplace gossip on ego depletion. Logically, employees with high sensitivity to interpersonal mistreatment who experience negative workplace gossip will experience a stronger level of ego depletion, leading to more political acts. Therefore, it can be reasonably proposed as a moderated mediation model (Edwards and Lambert 2007), that is, that the indirect effect of negative workplace gossip on political acts via ego depletion will be moderated by targets' sensitivity to interpersonal mistreatment. Specifically, higher levels of sensitivity to interpersonal mistreatment will not only exacerbate the impact of negative workplace gossip on targets' ego depletion, but will also magnify the indirect impact of negative workplace gossip on political acts through ego depletion. On the contrary, lower levels of sensitivity to 
interpersonal mistreatment will weaken the impact of negative workplace gossip on targets' ego depletion as well as reducing the indirect impact of negative workplace gossip on political acts through ego depletion. We therefore propose:

Hypothesis 5: The indirect effect of negative workplace gossip on targets' political acts via ego depletion is moderated by targets' sensitivity to interpersonal mistreatment, such that this relationship is stronger when targets' sensitivity to interpersonal mistreatment is higher.

Similarly, this study has constructed theoretical bases for the mediating effect of ego depletion on the relationship between negative workplace gossip and political acts, and has also outlined the moderating role of moral disengagement on the relationship between ego depletion and political acts. It is logical to infer that employees with high levels of moral disengagement who are targeted by negative workplace gossip will experience stronger levels of ego depletion, leading to more political acts. Therefore, this study proposes a moderated mediation model in which moral disengagement moderates the strength of the mediating mechanism for ego depletion in the relationship between negative workplace gossip and political acts. Specifically, high levels of moral disengagement will not only amplify the impact of ego depletion on political acts, but will also strengthen the indirect relationship between negative workplace gossip and political acts through ego depletion. Conversely, low levels of moral disengagement will not only decrease the impact of ego depletion on political acts, but will also weaken the indirect relationship between negative 
workplace gossip and political acts through ego depletion. We therefore propose the following hypothesis.

Hypothesis 6: The indirect effect of negative workplace gossip on targets' political acts via ego depletion is moderated by targets' moral disengagement, such that this relationship is stronger when targets' moral disengagement is higher.

\section{Method}

\subsection{Sample and Procedures}

We collected the data for this study using a three-wave time-lagged survey, leaving one month between each phase of collection. This method was chosen to reduce potential common method bias (CMB) (Cheng et al. 2020; Podsakoff et al. 2003). We chose five companies, all located in the Chinese city of Guangdong. With the help of human resources management, we distributed questionnaires to the employees. Every participant was assigned a number at the outset so they could be matched to each stage of the data collection. The first questionnaire collected basic demographic information, and measured perceptions of negative workplace gossip and sensitivity to interpersonal mistreatment. The second asked employees to rate their ego depletion and moral disengagement, while the third gathered information about their political acts. All these variables were rated by the employees themselves.

In the first stage, we distributed surveys to 506 employees, and received 431 usable answers - a response rate of $85.2 \%$. A month later, we sent the second questionnaire to the 
employees who had responded the first time, and 342 valid ones were returned - a response rate of $79.4 \%$ for this second stage. Another month later, for stage three, we asked those who had responded in stage two to fill out the final questionnaire. We received a total of 265 useable questionnaires back, generating a response rate of $77.5 \%$ for stage three. Of these 265 respondents, $56.2 \%$ were female, $27.9 \%$ had a junior or high school degree, $32.1 \%$ had a junior college degree, and the remaining $40 \%$ held Bachelor's or higher degrees. Just under half (49.8\%) were aged 25-35 years.

\subsection{Measures}

Unless otherwise noted, all the measures were rated on a five-point Likert scale ranging from 1 (strongly disagree) to 5 (strongly agree). They were translated into Chinese using a back-translation procedure (Brislin 1970).

Negative workplace gossip. Negative workplace gossip was measured by Chandra and Robinson's (2009) three-item scale. A sample item was “As recently as one month ago, false allegations were made about you". (Cronbach's alpha = .79).

Ego depletion. Ego depletion was measured using five items from Lin et al.'s (2016) measure, based on the work of Twenge et al. (2004). A sample item was "Generally speaking, I feel like my willpower is gone". (Cronbach's alpha $=.84)$.

Sensitivity to interpersonal mistreatment. Li et al.'s (2016) four-item scale was used to rate sensitivity to interpersonal mistreatment. A sample item was "I remember when my supervisor or co-workers lie to me". (Cronbach's alpha $=.77)$.

Moral disengagement. To measure moral disengagement, we employed Moore et al.'s 
(2012) eight-item scale. A sample item was "People who get mistreated have usually done something to bring it on themselves". (Cronbach's alpha $=.81$ ).

Political acts. We measured political acts by adopting Gabriel et al.'s (2018) four-item scale, adapted from Hochwarter et al.'s (2003) study. A sample item was "I spent time winning the approval of those (e.g., supervisors, managers) who can help me". (Cronbach's alpha $=.81)$.

Control variables. Previous research (e.g., Elbanna et al. 2014; Gabriel et al. 2018) has confirmed significant relationships between demographic characteristics and political acts. We therefore controlled employees' gender, age, education and tenure. We dummy-coded gender and education, with male coded as "1" and female coded as "2", high school diploma or less coded as "1", junior college degree coded as "2", and Bachelor's degree or above coded as " 3 ".

\section{Results}

\subsection{Confirmatory Factor Analysis and Common Method Variance Analysis}

Confirmatory factor analysis (CFA) was used to test the discriminant validities of all the variables through maximum likelihood estimation, using AMOS 23.0 (Cheng et al. 2020). The CFA results, presented in Table 1 , show a better fit $\left(\chi^{2}=388.60\right.$, df $=242$, IFI $=.93$, $\mathrm{TLI}=.92, \mathrm{CFI}=.93, \mathrm{RMSEA}=.05$ ) for the hypothesized five-factor model (i.e., negative workplace gossip, ego depletion, sensitivity to interpersonal mistreatment, moral disengagement and political acts) than for the alternative models.

In addition, to avoid potential $\mathrm{CMB}$, which can result from single source data collection 
in behavioral research, this study adopted Harman's single latent factor approach. As shown in Table 1, all the goodness-of-fit measures indicated a poor fit for the one-factor model $\left(\chi^{2}\right.$ $=1567.21, \mathrm{df}=252 ; \mathrm{RMSEA}=.14 ; \mathrm{IFI}=.34, \mathrm{TLI}=.27, \mathrm{CFI}=.34)$ but a good fit for the five-factor model. The chi-squared difference also indicated that the five-factor model yielded a significantly better fit than the one-factor model $\left(\Delta \chi^{2}=1178.61 ; \Delta \mathrm{df}=10 ; p<.01\right)$, suggesting that $\mathrm{CMB}$ was not problematic in this dataset.

[Table 1 near here]

\subsection{Descriptive Statistics}

The descriptive statistics, reliabilities and correlations of all the variables are listed in Table 2. The results showed that negative workplace gossip had a positive relationship with ego depletion $(r=.29, p<.01)$ as well as with political acts $(r=.24, p<.01)$, and ego depletion had a positive relationship with political acts $(r=.29, p<.01)$.

[Table 2 near here]

\subsection{Hypothesis Testing}

Hypotheses 1 and 2 were examined by hierarchical multiple regression analyses. The results, shown in Table 3, verified that negative workplace gossip was positively related to political acts $(\beta=.24, p<.01$, Model 6$)$. Hence, Hypothesis 1 is supported.

[Table 3 near here]

Hypothesis 2 proposed that ego depletion played a mediating role in the relationship between negative workplace gossip and political acts. The results suggested that: (1) 
negative workplace gossip was positively associated with ego depletion $(\beta=.29, p<.01$, Model 2); (2) ego depletion was positively related to political acts $(\beta=.28, p<.01$, Model 7); and (3) after placing ego depletion, the positive effect of negative workplace gossip on political acts decreased $(\beta=.17, p<.01$, Model 8$)$, while the positive correlation between ego depletion and political acts remained $(\beta=.23, p<.01$, Model 8$)$. Thus, Hypothesis 2 is partially supported.

In addition, we evaluated the statistical significance of the indirect effect by adopting the PRODCLIN tool presented by Edwards and Lambert (2007). The results indicated that negative workplace gossip had a significant indirect effect on political acts via ego depletion, as the $95 \%$ bias-corrected confidence interval did not include zero $(\mathrm{B}=.05,[.03, .10])$. Thus, Hypothesis 2 is further supported.

A four-step regression analysis was employed to test the moderating role of sensitivity to interpersonal mistreatment (Hypothesis 3) and moral disengagement (Hypothesis 4). The results, shown in Table 3, demonstrated that the interaction between negative workplace gossip and sensitivity to interpersonal mistreatment was positively related to ego depletion $(\beta=.15, p<.05$, Model 4$)$. To make the moderating effect much clearer, this study calculated two types of the mean of sensitivity to interpersonal mistreatment, one standard deviation and another below, as Aiken and West (1991) recommended. The interactive mode is illustrated in Fig. 2, which conformed to Hypothesis 3. More precisely, for targets higher in sensitivity to interpersonal mistreatment, negative workplace gossip was more positively correlated with ego depletion $(\beta=.30, p<.01)$; while the relationship was not significant 
for those with lower levels of sensitivity to interpersonal mistreatment $(\beta=.08$, n.s. $)$. This result provides plain support for Hypothesis 3.

[Fig. 2 near here]

Similarity, the interaction between ego depletion and moral disengagement was positively related to political acts $(\beta=.14, p<.05$, Model 10$)$. The interactive mode is illustrated in Fig. 3, which conformed to Hypothesis 4. More precisely, for targets higher in moral disengagement, ego depletion was more positively correlated with political acts $(\beta$ $=.25, p<.01)$; while the relationship was not significant with lower levels of moral disengagement $(\beta=.09$, n.s. $)$. This result provides plain support for Hypothesis 4 .

[Fig. 3 near here]

Edwards and Lambert's (2007) bootstrapping procedure was used to test the moderated mediation (Hypotheses 5 and 6). As shown in Table 4, the indirect impact of negative workplace gossip on political acts through ego depletion varied significantly across levels of sensitivity to interpersonal mistreatment $(\triangle \beta=.11, p<.01)$. Specifically, the indirect impact of negative workplace gossip on political acts through ego depletion was stronger when sensitivity to interpersonal mistreatment was high $(\beta=.11, p<.01)$ than when it was low $(\beta=.00$, n.s. $)$. Therefore, Hypothesis 5 is supported.

[Table 4 near here]

Similarly, as shown in Table 5, the indirect impact of negative workplace gossip on political acts through ego depletion varied significantly across levels of moral 
disengagement $(\Delta \beta=.10, p<.01)$. Specifically, the indirect impact of negative workplace gossip on political acts through ego depletion was stronger when moral disengagement was high $(\beta=.12, p<.01)$ than when it was low $(\beta=.02$, n.s. $)$. Therefore, Hypothesis 6 is supported.

[Table 5 near here]

\section{Discussion}

Many employees will become the subject of negative gossip at some point in their working lives, causing them detrimental outcomes and forcing them to find ways to reverse the disadvantageous situation. Using COR theory, this study provides insights into how this experience causes ego depletion and promotes political acts. In addition, by investigating the moderating roles of sensitivity to interpersonal mistreatment and moral disengagement, we have enhanced understanding of the boundary conditions of the process. Since negative workplace gossip places targets in an unfavorable position and causes them damage, managers need to pay attention to the phenomenon and make efforts to reduce its occurrence and address its negative effects. This research enriches the current literature and inspires new thinking on the topic.

\subsection{Theoretical Implications}

This study moves beyond the current literature in four aspects. Firstly, it advances our knowledge of negative workplace gossip by focusing on the potential for self-serving behaviors, namely political acts, to emerge as a relatively proactive reaction to reduce its negative effects. Although prior research has investigated targets' work-related behaviors as 
outcomes, it has mainly examined the impact on in-role and out-of-role behaviors in the workplace (Xie et al. 2019; Lee et al. 2016; Wu et al. 2018b; Babalola et al. 2019), all of which, from the resource-based perspective, are aimed only at preserving current resources by reducing devotion to work. However, according to COR (Hobfoll et al. 2018), when faced with the loss of resources, individuals can take additional actions to strive for new resources rather than just preventing current resources from being lost. An important type of self-benefiting workplace behavior - namely political acts, which can facilitate the resource acquisition process - is therefore neglected by the current literature. Our research provides valuable insights into this by highlighting how negative workplace gossip can trigger political acts.

Secondly, our findings enrich the literature on political acts by exploring the common but overlooked workplace phenomenon of negative gossip. Previous research has merely verified the limited antecedents of political acts, and has focused mainly on the influence of individual and contextual factors (Buchanan 2008), such as individuals' achievement objectives (Buchanan 2008) and the organization's political climate (Kidron and Vinarski Peretz 2018), leaving varied workplace conditions unexamined. Past researchers have called for more attention to be paid to examining why employees act politically in organizations (Buchanan 2008; Kidron and Vinarski Peretz 2018; Hochwarter et al. 2003). Thus, by introducing negative workplace gossip as a driver of political acts, the present study provides a useful supplement to the existing literature.

Thirdly, this study highlights the underlying mechanism of ego depletion through 
which negative workplace gossip impacts on political acts. Based on COR, we emphasize the significant loss of resources caused by negative workplace gossip, and how this reduction leads on to ego depletion and further undesirable employee behaviors (Baumeister 2003; Stucke and Baumeister 2006; Beedie and Lane 2012). Our findings suggest that negative workplace gossip is a resource-consuming experience that causes ego depletion, which in turn promotes political acts by the targets. By stressing this mediator, we highlight the importance of ego depletion and provide insights into the political acts that can flow from it.

Fourthly, this study demonstrates two important boundary conditions in the impact of negative workplace gossip, by investigating the moderating roles of sensitivity to interpersonal mistreatment and moral disengagement. The results verify that negative workplace gossip is especially detrimental to targets with high sensitivity to interpersonal mistreatment, since these individuals are more likely to find out they are being gossiped about and therefore undergo a higher level of ego depletion, resulting in a greater likelihood of them carrying out political acts. By exploring moral disengagement, we expand the present literature on the extent to which individuals may justify conducting self-interested behavior influenced by negative workplace gossip. Additionally, we contribute to COR theory by providing empirical support to verify that an individual's resource process is influenced by their personality.

\subsection{Managerial Implications}

Our findings highlight the importance of a strong managerial and organizational 
response to negative workplace gossip, given its impact on individuals and the organization. It had already been established that negative gossip, as a workplace stressor (De Gouveia et al. 2005; Wu et al. 2018b) and important factor of the workplace environment (Ye et al. 2019) causes serious issues for targets beyond damaged reputations (Kuo et al. 2015), impacting on targets' work performance and workplace behavior (Georganta et al. 2014; Zhou et al. 2019; Tian et al. 2019; Wu et al. 2018a, 2018b). However, our empirical results go further, providing important new evidence of the mechanisms involved in these effects, and clearly demonstrating the potential for self-serving behaviors, which may further influence organizational goals (Ferris et al. 1989). On the basis of our empirical findings, the managerial contributions of our study can be divided into three broad areas.

Firstly, our findings suggest that managers should consider taking practical steps to prevent and contain negative gossip in order to reduce its overall level in an organization, and to protect targets from being hurt. For example, managers could create value-based guidelines or rules which make clear that negative gossip is not tolerated in the organization (e.g. forbidding talking about the personal privacy of others in the office), backed up by sanctions against those who persistently flout the guidelines. The creation of organizationwide systems to back up this 'zero-tolerance' approach would deliver a coordinated approach across departments, help to ensure that individual episodes of negative gossip are dealt with early to prevent them spreading, and provide appropriate ways for employees to make managers aware of damaging situations or the targeting of individuals. Organizations themselves could also reduce the chances of certain types of negative gossip, for example 
around restructuring, promotions and redundancies, by disclosing correct information in a timely manner. Furthermore, given that gossip is also a social approach used by employees for communication and entertainment (Brady et al. 2017; Foster 2004; Kuo et al. 2015), its negative forms could be tempered by the creation of ample constructive communication opportunities in which team members can participate, such as regular team communications, one-to-many interviews and periodic events such as team dinners to satisfy employees' social needs.

Secondly, given our findings that the targets of negative gossip are likely to undergo high levels of ego depletion and to engage in political acts, managers could intensify their focus on guarding against resource depletion in individual employees. Our results highlight the importance of preventing targets falling into a state of ego depletion: this would promote their engagement with work rather than triggering self-serving behaviors. Managers should therefore watch for signs of ego depletion among individual staff members through regular communication and observation of their performance, and intervene promptly to help them replenish their resources and recover from ego depletion. These steps should include the provision of support for the targets of negative gossip in order to mitigate their pain (Xie et al. 2019). For example, managers could provide encouragement to promote targets' selfesteem, offer guidance to enhance their work-related focus, and suggest flexible working hours to facilitate gains in their mental and physical resources. In addition, companies could enhance employees' interpersonal skills and coping strategies when targeted by gossip by providing relevant training and organizing group activities which could promote team 
cohesion. This could be carried out proactively to equip employees to cope with negative gossip, rather than reactively when ego depletion may already be a factor.

Thirdly, since our empirical findings also show that the higher an employee's level of sensitivity to interpersonal mistreatment, the stronger the impact of negative workplace gossip on ego depletion, managers should consider adapting their recruitment and training policies accordingly. Our results suggest that companies may be well advised to recruit employees with low levels of sensitivity to interpersonal mistreatment in order to reduce the impact of negative gossip on ego depletion. A similar suggestion can be used with regard to the trait of moral disengagement: by employing staff with low levels of moral disengagement, firms can reduce the possible impact of ego depletion on political acts. At the same time, managers should provide training to employees with high levels of sensitivity to interpersonal mistreatment in order to reduce their sensitivity and attention to mistreatment. Furthermore, managers should monitor employees with high levels of moral disengagement to reduce the likelihood of them engaging in self-beneficial behaviors.

\subsection{Limitations and Future Research Directions}

The first limitation of this study relates to the use of self-reporting by the respondents, which was chosen because negative workplace gossip, ego depletion, sensitivity to interpersonal mistreatment, moral disengagement and political acts are subjective feelings. This method of measurement may give rise to CMB (Podsakoff et al. 2012). Although no CMB problem was shown in the statistical tests, the objective measurement method may be more explanatory. Secondly, accurately determining a causal relationship using time-lagged data 
is difficult. The results would be more convincing if the causal relationship between the variables could be determined by longitudinal studies. Thirdly, the process whereby negative workplace gossip leads to political acts could be affected by other personal factors, such as political skill, which describe individuals' natural ability to understand and influence others at work to achieve their goals (Treadway et al. 2005). Fourthly, in addition to COR theory, the relationship between negative workplace gossip and political acts could be explored from different theoretical perspectives, such as affective event theory. Finally, from a practical standpoint, future research should examine coping mechanisms for mitigating the effects of negative workplace gossip on employees' ego depletion, such as emotional intelligence, etc. 


\section{References}

Aiken, L. S. and West, S. G. (1991). Multiple regression: Testing and interpreting interactions. Sage Publications, Newbury Park, CA.

Babalola, M. T., Ren, S., Kobinah, T., Qu, Y. E., Garba, O. A., and Guo, L. (2019). Negative workplace gossip: Its impact on customer service performance and moderating roles of trait mindfulness and forgiveness. International Journal of Hospitality Management 80, 136-143.

Bandura, A. (1991). Social cognitive theory of self-regulation. Organizational Behavior and Human Decision Processes 50(2), 248-287.

Bandura, A. (1999). Social cognitive theory: An agentic perspective. Asian Journal of Social Psychology 2(1), 21-41.

Bandura, A. (2002). Selective moral disengagement in the exercise of moral agency. Journal of Moral Education, 31(2), 101-119.

Bandura, A., Barbaranelli, C., Caprara, G. V., and Pastorelli, C. (1996). Mechanisms of moral disengagement in the exercise of moral agency. Journal of Personality and Social Psychology 71(2), 364-374.

Baumeister, R. F. (2002). Ego depletion and self-control failure: An energy model of the self's executive function. Self and Identity 1(2), 129-136.

Baumeister, R. F. (2003). Ego depletion and self-regulation failure: A resource model of self-control. Alcoholism: Clinical and Experimental Research 27(2), 281-284.

Baumeister, R. F., Bratslavsky, E., Finkenauer, C., and Vohs, K. D. (2001). Bad is stronger 
than good. Review of General Psychology 5(4), 323-370.

Baumeister, R. F., Vohs, K. D., and Tice, D. M. (2007). The strength model of self-control. Current Directions in Psychological Science 16(6), 351-355.

Brady, D. L., Brown, D. J., and Liang, L. H. (2017). Moving beyond assumptions of deviance: The reconceptualization and measurement of workplace gossip. Journal of Applied Psychology 102(1), 1-25.

Beedie, C. J., and Lane, A. M. (2012). The role of glucose in self-control: Another look at the evidence and an alternative conceptualization. Personality and Social Psychology Review 16(2), 143-153.

Beersma, B., and Van Kleef, G. A. (2011). How the grapevine keeps you in line: Gossip increases contributions to the group. Social Psychological and Personality Science 2(6), 642-649.

Blickle, G., Schneider, P. B., Liu, Y., and Ferris, G. R. (2011). A predictive investigation of reputation as mediator of the political-skill/career-success relationship. Journal of Applied Social Psychology 41(12), 3026-3048.

Brislin, R. W. (1970). Back-translation for cross-cultural research. Journal of Cross-cultural Psychology 1(3), 185-216.

Buchanan, D. A. (2008). You stab my back, I'll stab yours: Management experience and perceptions of organization political behaviour. British Journal of Management 19(1), 49-64.

Bunk, J. A., and Magley, V. J. (2011). Sensitivity to interpersonal treatment in the 
workplace: Scale development and initial validation. Journal of Occupational and Organizational Psychology 84(2), 395-402.

Chandra, G., and Robinson, S. L. (2009). They're talking about me again: The impact of being the target of gossip on emotional distress and withdrawal. Presented at the Meeting of Academy of Management, Chicago, IL, USA.

Chang, C. H., Rosen, C. C., and Levy, P. E. (2009). The relationship between perceptions of organizational politics and employee attitudes, strain, and behavior: A metaanalytic examination. Academy of Management Journal 52(4), 779-801.

Cheng, B., Zhou, X., Guo, G., and Yang, K. (2020). Perceived overqualification and cyberloafing: A moderated-mediation model based on equity theory. Journal of Business Ethics 164(5), 565-577.

De Gouveia, C. M., Van Vuuren, L. J., and Crafford, A. (2005). Towards a typology of gossip in the workplace. SA Journal of Human Resource Management 3(2), 56-68.

Detert, J. R., Treviño, L. K., and Sweitzer, V. L. (2008). Moral disengagement in ethical decision making: a study of antecedents and outcomes. Journal of Applied Psychology 93(2), 374-391.

Dunbar, R. I. (2004). Gossip in evolutionary perspective. Review of General Psychology $8(2), 100-110$.

DuBrin, A. J. (2009). Political behavior in organizations. Sage, Thousand Oaks, CA.

Drory, A., and Romm, T. (1990). The definition of organizational politics: A review. Human Relations 43(11), 1133-1154. 
Edwards, J. R. and Lambert, L. S. (2007). Methods for integrating moderation and mediation: A general analytical framework using moderated path analysis. Psychological Methods 12(1), 1-22.

Elbanna, S., C. Thanos, I., and M. Papadakis, V. (2014). Understanding how the contextual variables influence political behaviour in strategic decision-making: A constructive replication. Journal of Strategy and Management 7(3), 226-250.

Ellwardt, L., Labianca, G. J., and Wittek, R. (2012). Who are the objects of positive and negative gossip at work?: A social network perspective on workplace gossip. Social Networks 34(2), 193-205.

Feinberg, M., Willer, R., Stellar, J., and Keltner, D. (2012). The virtues of gossip: Reputational information sharing as prosocial behavior. Journal of Personality and Social Psychology 102(5), 1015-1030.

Ferris, G. R., Russ, G. S., and Fandt, P. M. (1989). Politics in organizations. In R. A. Giacalone and P. Rosenfeld (eds.), Impression management in the organization (pp. 143-170). Lawrence Erlbaum, Hillsdale, NJ.

Ferris, G. R., Adams, G., Kolodinsky, R. W., Hochwarter, W. A., and Ammeter, A. P. (2002). Perceptions of organizational politics: Theory and research directions. In F. Dansereau and F. J. Yammarino (eds.), Research in multi-level issues (pp. 179-254). ElsevierScience/JAI Press, Oxford, UK.

Fischer, P., Kastenmüller, A., and Asal, K. (2012). Ego depletion increases risk-taking. The Journal of Social Psychology 152(5), 623-638. 
Foster, E. K. (2004). Research on gossip: Taxonomy, methods, and future directions. Review of General Psychology 8(2), 78-99.

Gabriel, A. S., Koopman, J., Rosen, C. C., and Johnson, R. E. (2018). Helping others or helping oneself? An episodic examination of the behavioral consequences of helping at work. Personnel Psychology 71(1), 85-107.

Georganta, K., Panagopoulou, E., and Montgomery, A. (2014). Talking behind their backs: Negative gossip and burnout in hospitals. Burnout Research 1(2), 76-81.

Gino, F., Schweitzer, M. E., Mead, N. L., and Ariely, D. (2011). Unable to resist temptation: How self-control depletion promotes unethical behavior. Organizational Behavior and Human Decision Processes 115(2), 191-203.

Grosser, T., Kidwell, V., and Labianca, G. J. (2012). Hearing it through the grapevine: Positive and negative workplace gossip. Organizational Dynamics 41(1), 52-61.

Hagger, M. S., and Chatzisarantis, N. L. (2016). A multilab preregistered replication of the ego-depletion effect. Perspectives on Psychological Science 11(4), 546-573.

Halbesleben, J. R., Neveu, J. P., Paustian-Underdahl, S. C., and Westman, M. (2014). Getting to the "COR": Understanding the role of resources in conservation of resources theory. Journal of Management 40(5), 1334-1364.

Hobfoll, S. E. (1989). Conservation of resources: A new attempt at conceptualizing stress. American Psychologist 44(3), 513-524.

Hobfoll, S. E., Halbesleben, J., Neveu, J. P., and Westman, M. (2018). Conservation of resources in the organizational context: The reality of resources and their 
consequences. Annual Review of Organizational Psychology and Organizational Behavior 5, 103-128.

Hochwarter, W. A., Kacmar, C., Perrewe, P. L., and Johnson, D. (2003). Perceived organizational support as a mediator of the relationship between politics perceptions and work outcomes. Journal of Vocational Behavior 63(3), 438-456.

Kidron, A., and Vinarski Peretz, H. (2018). Organizational political climate and employee engagement in political behavior in public sector organizations: A mixed methods study. International Journal of Organizational Analysis 26(4), 773-795.

Kniffin, K. M., and Wilson, D. S. (2010). Evolutionary perspectives on workplace gossip: Why and how gossip can serve groups. Group and Organization Management 35(2), $150-176$.

Kuo, C. C., Chang, K., Quinton, S., Lu, C. Y., and Lee, I. (2015). Gossip in the workplace and the implications for HR management: A study of gossip and its relationship to employee cynicism. International Journal of Human Resource Management 26(18), 2288-2307.

Kurland, N. B., and Pelled, L. H. (2000). Passing the word: Toward a model of gossip and power in the workplace. Academy of Management Review 25(2), 428-438.

Landells, E. M., and Albrecht, S. L. (2017). The positives and negatives of organizational politics: A qualitative study. Journal of Business and Psychology 32(1), 41-58.

Langford, P. H. (2000). Importance of relationship management for the career success of Australian managers. Australian Journal of Psychology 52(3), 163-168. 
Lee, H. M., Chou, M. J., and Wu, H. T. (2016). Effect of workplace negative gossip on preschool teachers' job performance: Coping strategies as moderating variable. European Journal of Research and Reflection in Management Sciences 4(6), 1-13.

Liden, R. C., Wayne, S. J., and Sparrowe, R. T. (2000). An examination of the mediating role of psychological empowerment on the relations between the job, interpersonal relationships, and work outcomes. Journal of Applied Psychology 85(3), 407-416.

Li, Y., Chen, M., Lyu, Y., and Qiu, C. (2016). Sexual harassment and proactive customer service performance: The roles of job engagement and sensitivity to interpersonal mistreatment. International Journal of Hospitality Management 54, 116-126.

Lin, S. H. J., Ma, J., and Johnson, R. E. (2016). When ethical leader behavior breaks bad: How ethical leader behavior can turn abusive via ego depletion and moral licensing. Journal of Applied Psychology 101(6), 815-830.

Liu, Y., and Berry, C. M. (2013). Identity, moral, and equity perspectives on the relationship between experienced injustice and time theft. Journal of Business Ethics 118(1), 7383.

Liu, X. Y., Kwan, H. K., and Zhang, X. (2020). Introverts maintain creativity: A resource depletion model of negative workplace gossip. Asia Pacific Journal of Management $37(1), 1-20$.

Mayes, B. T., and Allen, R. W. (1977). Toward a definition of organizational politics. Academy of Management Review 2(4), 672-678.

Michelson, G., and Mouly, V. S. (2002). 'You didn't hear it from us but...': Towards an 
understanding of rumour and gossip in organisations. Australian Journal of Management 27, 57-65.

Moore, C., Detert, J. R., Klebe Treviño, L., Baker, V. L., and Mayer, D. M. (2012). Why employees do bad things: Moral disengagement and unethical organizational behavior. Personnel Psychology 65(1), 1-48.

Mills, C. (2010). Experiencing gossip: The foundations for a theory of embedded organizational gossip. Group and Organization Management 35(2), 213-240.

Neuman, J. H., and Baron, R. A. (1998). Workplace violence and workplace aggression: Evidence concerning specific forms, potential causes, and preferred targets. Journal of Management 24(3), 391-419.

Podsakoff, P. M., MacKenzie, S. B., Lee, J., Podsakoff, N. P. (2003). Common method biases in behavioral research: A critical review of the literature and recommended remedies. Journal of Applied Psychology 88(5), 879-903.

Podsakoff, P. M., MacKenzie, S. B., Podsakoff, N. P. (2012). Sources of method bias in social science research and recommendations on how to control it. Annual Review of Psychology 63(1), 539-569.

Rosen, C. C., Koopman, J., Gabriel, A. S., and Johnson, R. E. (2016). Who strikes back? A daily investigation of when and why incivility begets incivility. Journal of Applied Psychology 101(11), 1620-1634.

Schmeichel, B. J., Vohs, K. D., and Baumeister, R. F. (2003). Intellectual performance and ego depletion: Role of the self in logical reasoning and other information processing. 
Journal of Personality and Social Psychology 85(1), 33-46.

Schmidt, K. H., and Neubach, B. (2007). Self-control demands: A source of stress at work. International Journal of Stress Management 14(4), 398-416.

Stucke, T. S., and Baumeister, R. F. (2006). Ego depletion and aggressive behavior: Is the inhibition of aggression a limited resource? European Journal of Social Psychology $36(1), 1-13$

Tian, Q. T., Song, Y., Kwan, H. K., and Li, X. (2019). Workplace gossip and frontline employees' proactive service performance. Service Industries Journal 39(1), 25-42.

Treadway, D. C., W. A. Hochwarter, C. J. Kacmar and G. R. Ferris (2005). Political will, political skill, and political behavior. Journal of Organizational Behavior 26(3), 229245.

Turnley, W. H., and Bolino, M. C. (2001). Achieving desired images while avoiding undesired images: Exploring the role of self-monitoring in impression management. Journal of Applied Psychology 86(2), 351-360.

Twenge, J., Muraven, M., and Tice, D. (2004). Measuring state: Reliability, validity, and correlations with physical and psychological stress (Unpublished manuscript). San Diego State University, San Diego, CA.

Wu, J., Balliet, D., and Van Lange, P. A. (2016). Reputation, gossip, and human cooperation. Social and Personality Psychology Compass 10(6), 350-364.

Wu, L. Z., Birtch, T. A., Chiang, F. F., and Zhang, H. (2018b). Perceptions of negative workplace gossip: A self-consistency theory framework. Journal of Management 
44(5), 1873-1898.

Wu, X., Kwan, H. K., Wu, L. Z., and Ma, J. (2018a). The effect of workplace negative gossip on employee proactive behavior in China: The moderating role of traditionality. Journal of Business Ethics 148(4), 801-815.

Ye, Y., Zhu, H., Deng, X., and Mu, Z. (2019). Negative workplace gossip and service outcomes: An explanation from social identity theory. International Journal of Hospitality Management 82, 159-168.

Xie, J., Huang, Q., Wang, H., and Shen, M. (2019). Perish in gossip? Nonlinear effects of perceived negative workplace gossip on job performance. Personnel Review 49(2), $389-405$.

Zhou, A., Liu, Y., Su, X., and Xu, H. (2019). Gossip fiercer than a tiger: Effect of workplace negative gossip on targeted employees' innovative behavior. Social Behavior and Personality 47(5), 1-11. 


\section{Figure legends}

Fig. 1 The conceptual model of this study

Fig. 2 The interactive effects of negative workplace gossip and sensitivity to interpersonal mistreatment on ego depletion

Fig. 3 The interactive effects of ego depletion and moral disengagement on political acts 


\section{Table legends}

Table 1 Confirmatory factor analysis results

Table 2 Means, standard deviations, and correlations of all variables in this study

Table 3 Results of hypotheses testing.

Table 4 Results of the moderated path analysis $(\mathrm{N}=265)$

Table 5 Results of the moderated path analysis $(N=265)$ 


\section{Figures}

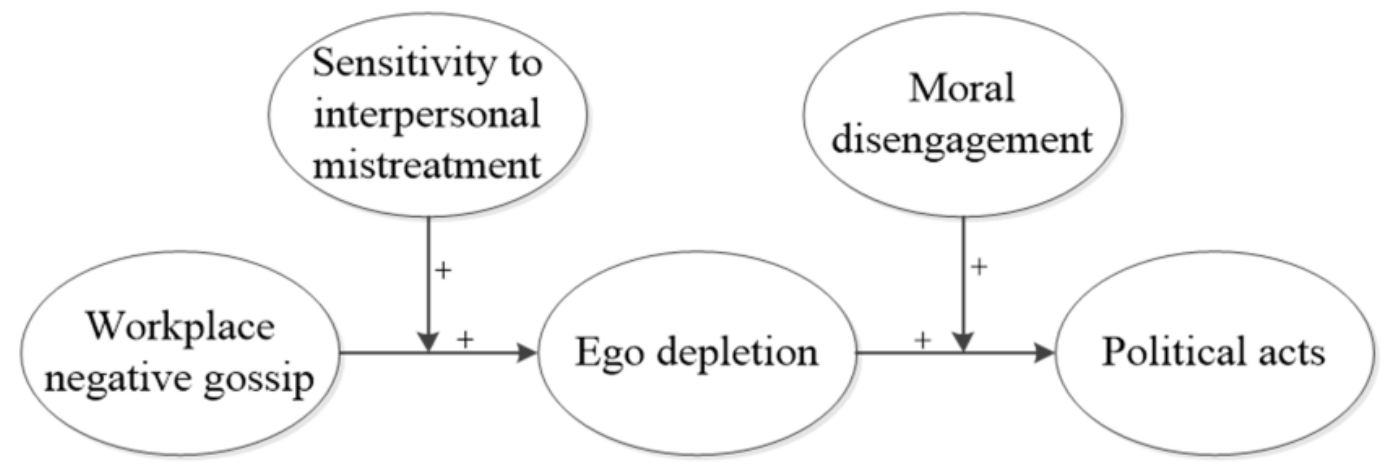

Fig. 1 


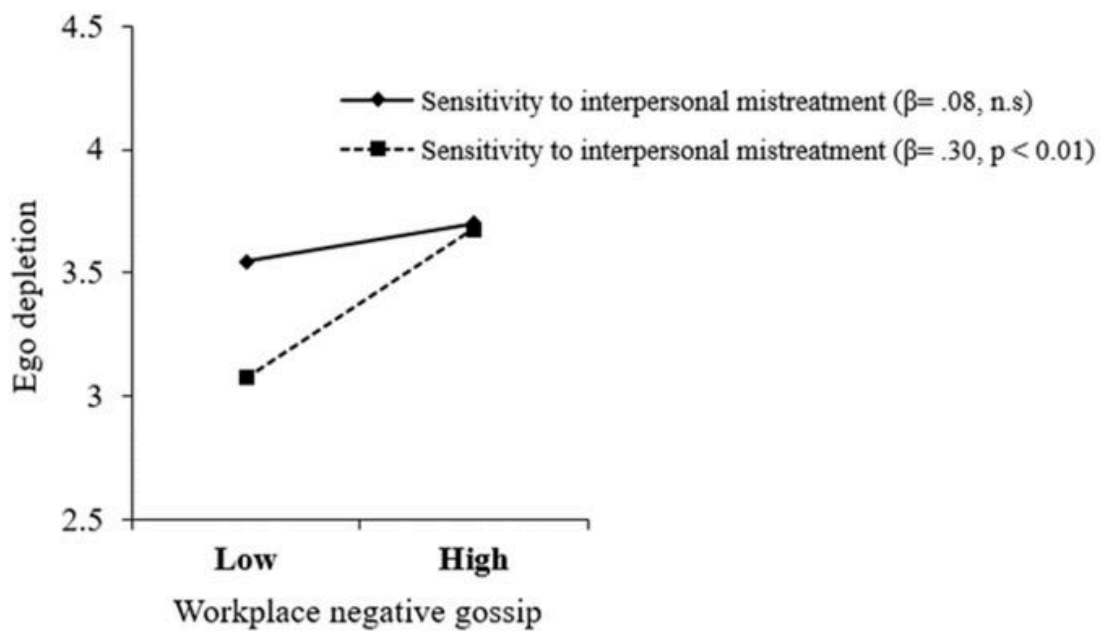

Fig. 2 


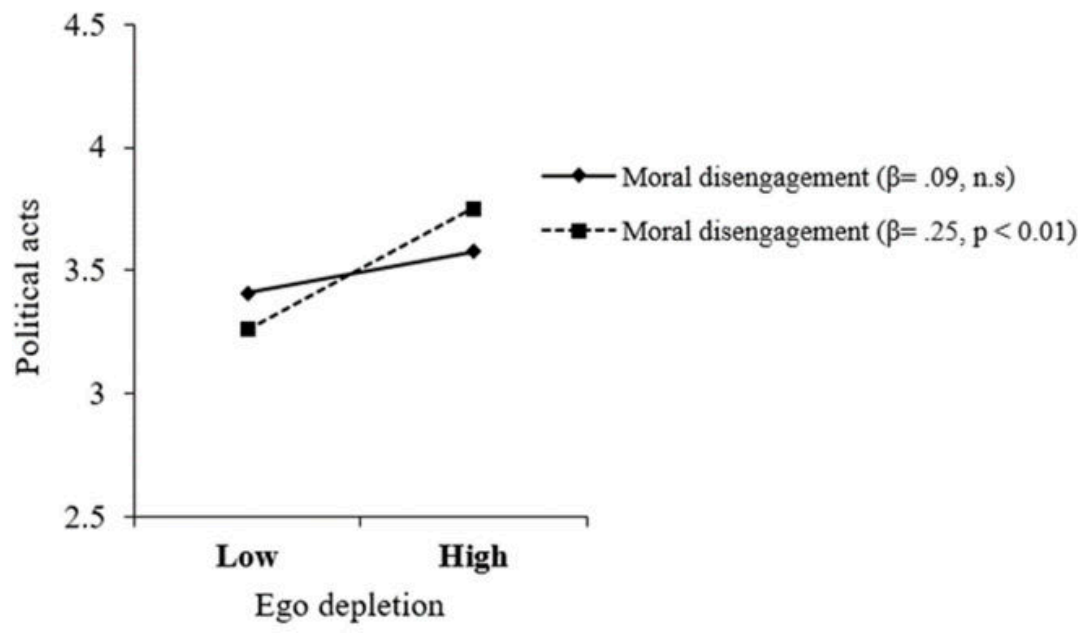

Fig. 3 


\section{Tables}

Table 1. Confirmatory factor analysis results

\begin{tabular}{|c|c|c|c|c|c|c|c|}
\hline Model & $\chi^{2}$ & $\mathrm{df}$ & $\chi^{2} / \mathrm{df}$ & IFI & TLI & CFI & RMSEA \\
\hline Baseline model (five-factor model) & 388.60 & 242 & 1.61 & .93 & .92 & .93 & .05 \\
\hline \multicolumn{8}{|c|}{ Four-factor model 1: negative workplace gossip and ego depletion } \\
\hline \multicolumn{8}{|l|}{ were combined into one factor } \\
\hline \multicolumn{8}{|c|}{ Four-factor model 2: negative workplace gossip and political acts } \\
\hline & 616.91 & 246 & 2.51 & .82 & .79 & .81 & .08 \\
\hline \multicolumn{8}{|l|}{ were combined into one factor } \\
\hline \multicolumn{8}{|c|}{ Four-factor model 3: negative workplace gossip and sensitivity to } \\
\hline \multicolumn{8}{|c|}{ Four-factor model 4: ego depletion and political acts were combined } \\
\hline \multicolumn{8}{|l|}{ into one factor } \\
\hline \multicolumn{8}{|c|}{ Four-factor model 5: ego depletion and sensitivity to interpersonal } \\
\hline & 638.79 & 246 & 2.60 & .81 & .78 & .80 & .08 \\
\hline \multicolumn{8}{|c|}{ mistreatment were combined into one factor } \\
\hline \multicolumn{8}{|c|}{ Four-factor model 6: political acts and sensitivity to interpersonal } \\
\hline & 631.24 & 246 & 2.57 & .81 & .78 & .81 & .08 \\
\hline \multicolumn{8}{|c|}{ mistreatment were combined into one factor } \\
\hline One-factor model & 1567.21 & 252 & 6.22 & .34 & .27 & .34 & .14 \\
\hline
\end{tabular}

Notes: $N=265 . \mathrm{IFI}=$ incremental fit index $; \mathrm{CFI}=$ comparative fit index $; \mathrm{TLI}=$ Tucker-

Lewis coefficient; RMSEA = root-mean-square error of approximation. 
Table 2. Means, standard deviations, and correlations of all variables in this study

\begin{tabular}{|c|c|c|c|c|c|c|c|c|c|c|}
\hline Variables & Mean & SD & 1 & 2 & 3 & 4 & 5 & 6 & 7 & 8 \\
\hline 1. Gender & 1.56 & .50 & & & & & & & & \\
\hline 2. Age & 2.79 & 1.37 & $.16^{*}$ & & & & & & & \\
\hline 3. Education & 2.12 & .82 & -.10 & $-.21 * *$ & & & & & & \\
\hline 4. Tenure & 2.42 & 1.15 & .05 & $.24 * *$ & $-.13^{*}$ & & & & & \\
\hline 5. Negative workplace gossip & 2.08 & .73 & -.01 & -.01 & .05 & -.01 & & & & \\
\hline 6. Ego depletion & 2.30 & .75 & -.04 & .01 & $.12 *$ & -.02 & $.29 * *$ & & & \\
\hline 7. Political acts & 1.93 & .60 & -.05 & .07 & .09 & -.05 & $.24 * *$ & $.29 * *$ & & \\
\hline \multicolumn{11}{|c|}{ 8. Sensitivity to interpersonal } \\
\hline mistreatment & & & & & & & & & & \\
\hline 9. Moral disengagement & 3.41 & 0.69 & -.09 & .02 & .02 & -.08 & $-.12 *$ & -.01 & .01 & .02 \\
\hline
\end{tabular}

Notes: $N=265 ;{ }^{*} p<.05 ;{ }^{* *} p<0.01$. 
Table 3. Results of hypotheses testing.

\begin{tabular}{|c|c|c|c|c|c|c|c|c|c|c|}
\hline & \multicolumn{4}{|c|}{ ego depletion } & \multicolumn{6}{|c|}{ political acts } \\
\hline & M1 & M2 & M3 & M4 & M5 & M6 & M7 & M8 & M9 & M10 \\
\hline \multicolumn{11}{|l|}{ Control variable } \\
\hline Gender & -.03 & -.03 & -.03 & -.04 & -.06 & -.06 & -.05 & -.05 & -.05 & -.05 \\
\hline Age & .04 & .04 & .05 & .04 & .11 & .11 & .10 & .10 & .10 & .12 \\
\hline Education & $.13^{*}$ & .12 & .11 & .11 & .10 & .09 & .07 & .07 & .07 & .05 \\
\hline Tenure & -.02 & -.02 & -.01 & -.01 & -.06 & -.06 & -.06 & -.06 & -.06 & -.06 \\
\hline \multicolumn{11}{|l|}{ Independent variable } \\
\hline Negative workplace gossip & & $.29 * *$ & $.26^{* *}$ & $.25 * *$ & & $.24 * *$ & & $.17 * *$ & & \\
\hline \multicolumn{11}{|l|}{ Mediator } \\
\hline ego depletion & & & & & & & $.28 * *$ & $.23 * *$ & $.28 * *$ & $.27 * *$ \\
\hline \multicolumn{11}{|l|}{ Moderator } \\
\hline sensitivity to interpersonal mistreatment & & & $-.16^{*}$ & $-.17 * *$ & & & & & & \\
\hline moral disengagement & & & & & & & & & .003 & .01 \\
\hline \multicolumn{11}{|l|}{ Interaction } \\
\hline \multicolumn{11}{|l|}{$\begin{array}{l}\text { negative workplace gossip } \times \text { sensitivity to } \\
\text { interpersonal mistreatment }\end{array}$} \\
\hline ego depletion $\times$ moral disengagement & & & & & & & & & & $.14 *$ \\
\hline$F$ & 1.15 & $5.77 * *$ & $6.06 * *$ & $6.24 * *$ & 1.53 & $4.40^{* *}$ & $5.58 * *$ & $6.08 * *$ & $4.64 * *$ & $4.81 * *$ \\
\hline$\Delta F$ & 1.15 & $23.85 * *$ & $6.82 *$ & $6.57^{*}$ & 1.53 & $15.51^{* *}$ & $21.31 * *$ & $13.42 *$ & .002 & $5.38 *$ \\
\hline$R^{2}$ & .02 & .10 & .12 & .15 & .02 & .08 & .10 & .12 & .10 & .12 \\
\hline$\Delta R^{2}$ & .02 & .08 & .02 & .02 & .02 & .06 & .07 & .05 & .00 & .02 \\
\hline
\end{tabular}

Notes: $N=265 ;{ }^{*} p<.05 ;{ }^{* *} p<.01$. 
Table 4. Results of the moderated path analysis $(\mathrm{N}=265)$

\begin{tabular}{|c|c|c|c|c|c|}
\hline \multirow{3}{*}{ Moderator variable } & \multicolumn{5}{|c|}{ Negative workplace gossip $(X) \rightarrow$ ego depletion $(M) \rightarrow$ political acts $(Y)$} \\
\hline & \multicolumn{2}{|l|}{ Stage } & \multicolumn{3}{|l|}{ Effect } \\
\hline & $\begin{array}{l}\text { First } \\
\left(P_{M X}\right)\end{array}$ & $\begin{array}{l}\text { Second } \\
\left(P_{Y M}\right)\end{array}$ & $\begin{array}{l}\text { Direct effects } \\
\left(P_{Y X}\right)\end{array}$ & $\begin{array}{l}\text { Indirect effects } \\
\left(P_{Y M} P_{M X}\right)\end{array}$ & $\begin{array}{l}\text { Total effects } \\
\left(P_{Y X}+P_{Y M} P_{M X}\right)\end{array}$ \\
\hline $\begin{array}{l}\text { Simple paths for low sensitivity to interpersonal } \\
\text { mistreatment }\end{array}$ & .11 & .01 & $.14^{*}$ & -.00 & $.14^{*}$ \\
\hline $\begin{array}{l}\text { Simple paths for high sensitivity to interpersonal } \\
\text { mistreatment }\end{array}$ & $.41 * *$ & $.27 * *$ & $.08^{*}$ & $.11 * *$ & $.19 * *$ \\
\hline Differences & $.30 * *$ & $.26^{* *}$ & -.06 & $.11 * *$ & .05 \\
\hline
\end{tabular}

${ }^{*} p<.05,{ }^{* *} p<.01$

Note: $P_{M X}$ : Path from negative workplace gossip to ego depletion; $P_{Y M}$ : Path from ego depletion to political acts; $P_{Y X}$ : Path from negative workplace gossip to political acts. Low sensitivity to interpersonal mistreatment refers to one standard deviation below the mean value of sensitivity to interpersonal mistreatment; High sensitivity to interpersonal mistreatment refers to one standard deviation above the mean value of sensitivity to interpersonal mistreatment. Tests of differences for the direct, indirect, and total effects were based on bias-corrected confidence intervals obtained from bootstrapping estimates. 
Table 5. Results of the moderated path analysis $(N=265)$

\begin{tabular}{|c|c|c|c|c|c|}
\hline \multirow{4}{*}{ Moderator variable } & \multicolumn{5}{|c|}{ Negative workplace gossip $(X) \rightarrow$ ego depletion $(M) \rightarrow$ political acts $(Y)$} \\
\hline & \multicolumn{2}{|l|}{ Stage } & \multicolumn{3}{|l|}{ Effect } \\
\hline & First & Second & Direct effects & Indirect effects & Total effects \\
\hline & $\left(P_{M X}\right)$ & $\left(P_{Y M}\right)$ & $\left(P_{Y X}\right)$ & $\left(P_{Y M} P_{M X}\right)$ & $\left(P_{Y X}+P_{Y M} P_{M X}\right)$ \\
\hline Simple paths for low moral disengagement & $.23^{* *}$ & .08 & $.12 * *$ & .02 & $.14^{* *}$ \\
\hline Simple paths for high moral disengagement & $.42 * *$ & $.28 * *$ & $.18 * *$ & $.12 * *$ & $.29 * *$ \\
\hline Differences & .19 & $.20 * *$ & .06 & $.10 * *$ & $.16^{*}$ \\
\hline
\end{tabular}

${ }^{*} p<.05,{ }^{* *} p<.01$

Note: $P_{M X}$ : Path from negative workplace gossip to ego depletion; $P_{Y M}$ : Path from ego depletion to political acts; $P_{Y X}$ : Path from negative workplace gossip to political acts. Low moral disengagement refers to one standard deviation below the mean value of moral disengagement; High moral disengagement refers to one standard deviation above the mean value of moral disengagement. Tests of differences for the direct, indirect, and total effects were based on bias-corrected confidence intervals obtained from bootstrapping estimates. 